\title{
Mechanical Behavior Assessment of Ti-6Al-4V ELI Alloy Produced by Laser Powder Bed Fusion
}

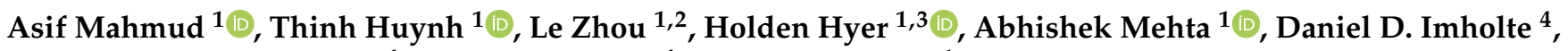 \\ Nicolas E. Woolstenhulme ${ }^{4}$, Daniel M. Wachs ${ }^{4}$ and Yongho Sohn ${ }^{1, *}$ \\ 1 Department of Materials Science and Engineering, University of Central Florida, Orlando, FL 32751, USA; \\ AMahmud@Knights.ucf.edu (A.M.); huynh.thinh96@Knights.ucf.edu (T.H.); le.zhou@marquette.edu (L.Z.); \\ hyerhc@ornl.gov (H.H.); abhi@Knights.ucf.edu (A.M.) \\ 2 Department of Mechanical Engineering, Marquette University, Milwaukee, WI 53233, USA \\ 3 Fusion Energy Division, Oak Ridge National Laboratory, Oak Ridge, TN 37830, USA \\ 4 Idaho National Laboratory, Idaho Falls, ID 83415, USA; devin.imholte@inl.gov (D.D.I.); \\ nicolas.woolstenhulme@inl.gov (N.E.W.); daniel.wachs@inl.gov (D.M.W.) \\ * Correspondence: ysohn@ucf.edu
}

Citation: Mahmud, A.; Huynh, T.; Zhou, L.; Hyer, H.; Mehta, A.;

Imholte, D.D.; Woolstenhulme, N.E.; Wachs, D.M.; Sohn, Y. Mechanical Behavior Assessment of Ti-6Al-4V ELI Alloy Produced by Laser Powder Bed Fusion. Metals 2021, 11, 1671. https://doi.org/10.3390/met11111671

Academic Editor: Reza Ghomashchi

Received: 3 September 2021

Accepted: 14 October 2021

Published: 20 October 2021

Publisher's Note: MDPI stays neutral with regard to jurisdictional claims in published maps and institutional affiliations.

Copyright: (C) 2021 by the authors. Licensee MDPI, Basel, Switzerland. This article is an open access article distributed under the terms and conditions of the Creative Commons Attribution (CC BY) license (https:/ / creativecommons.org/licenses/by/ $4.0 /)$.

\begin{abstract}
The present work correlates the quasi-static, tensile mechanical properties of additively manufactured Ti-6Al-4V extra low interstitial (ELI, Grade 23) alloy to the phase constituents, microstructure, and fracture surface characteristics that changed with post-heat treatment of stress relief $\left(670{ }^{\circ} \mathrm{C}\right.$ for $5 \mathrm{~h}$ ) and hot isostatic pressing (HIP with $100 \mathrm{MPa}$ at $920{ }^{\circ} \mathrm{C}$ for $2 \mathrm{~h}$ under an Ar atmosphere). Ti-6Al-4V ELI alloy tensile specimens in both the horizontal (i.e., $\mathrm{X}$ and $\mathrm{Y}$ ) and vertical (Z) directions were produced by the laser powder bed fusion (LPBF) technique. Higher yield strength $(1141 \mathrm{MPa})$, higher tensile strength $(1190 \mathrm{MPa})$, but lower elongation at fracture $(6.9 \%)$, along with mechanical anisotropy were observed for as-stress-relieved (ASR) samples. However, after HIP, consistent and isotropic mechanical behaviors were observed with a slight reduction in yield strength $(928 \mathrm{MPa})$ and tensile strength $(1003 \mathrm{MPa})$, but with a significant improvement in elongation at fracture (16.1\%). Phase constituents of acicular $\alpha^{\prime}$ phase in ASR and lamellar $\alpha+\beta$ phases in HIP samples were observed and quantified to corroborate the reduction in strength and increase in ductility. The anisotropic variation in elongation at fracture observed for the ASR samples, particularly built in the build $(Z)$ direction, was related to the presence of "keyhole" porosity.
\end{abstract}

Keywords: laser powder bed fusion; titanium alloy; hot isostatic pressing; phase transformations

\section{Introduction}

Additive manufacturing (AM), commonly known as 3D printing, typically refers to a process in which an engineering component is built, layer-by-layer, close to their final (net) shape. This net-shape capability of manufacturing with a high degree of resolution from a computer aided design (CAD) model and the ability of powder recycling makes the AM technology an excellent route for customized manufacturing. The high cooling rates and high thermal gradient during the build, for example, through laser-based AM, leads to a very fine microstructure and the formation of columnar grains that can create anisotropy in the mechanical properties [1-5]. The as-built AM components can suffer from manufacturing defects such as keyhole porosity and lack-of-fusion flaws [6-8]. The ability to produce a fine microstructure in components can lead to a higher strength but at the expense of reduced ductility and fracture toughness. Consequently, post-AM heat treatment has become an indispensable tool for the AM components in order to reduce some of the fabrication limitations and to obtain the desired mechanical properties [9-17]. While the challenge in AM may be defined by manufacturing components with a combination of superior strength, ductility, and fracture toughness in the as-built state [11,18,19], heat treatment of the component has always been a part of the manufacturing process for any manufacturing process. 
The high specific strength, good corrosion resistance, excellent biocompatibility, and low radioisotope transmutation under neutron bombardment of titanium alloys enable numerous applications in aerospace, biomedical, petrochemical, and specialty nuclear applications. The most popular titanium alloy, also recognized as the "workhorse alloy" in the titanium industry is Ti-6Al-4V, which consists of an $\alpha+\beta$ microstructure, where $\alpha$ (stabilized by $\mathrm{Al}$ ) is the low temperature hexagonal close packed (hcp) phase and $\beta$ (stabilized by V) is the high temperature body centered cubic (bcc) phase [20].

The as-built microstructure of the AM built Ti-6Al-4V components tends to be fine, needle-shaped, acicular $\alpha^{\prime}$ martensite because of the high cooling rate, although at times, Widmanstätten and $\alpha+\beta$ structures can be observed depending on the powder-based manufacturing process employed [17,20-23]. Columnar $\beta$ grains oriented in the build direction $(Z)$ can appear in the microstructure, which suggests that during solidification, the high temperature $\beta$ phase nucleates onto itself and grows across the build layers [17,20-23]. Application of stress-relief treatment minimizes the residual stresses typically observed in the as-built [24-29] part, and hot-isostatic pressing (HIP) leads to a significant improvement in ductility and fatigue strength by closing the pores and flaws [30-33]. Qiu et al. [22] examined the anisotropy in ductility for the selective laser melting (SLM) built Ti-6Al$4 \mathrm{~V}$ alloy, both in the as-built condition and after HIP, and reported an improvement in ductility with a reduction in strength, but anisotropy in ductility was reported to persist. Kasperovich et al. [34] reported higher \% elongation at fracture of $19.4 \%$, yield strength of $885 \mathrm{MPa}$, tensile strength of $973 \mathrm{MPa}$, and Young's modulus of $115.4 \mathrm{GPa}$ by a twostep heat treatment. Leuders et al. [32] also reported an improvement in \% elongation at fracture by heat treatment and HIP of Ti-6Al-4V alloy. Vrancken et al. [35] carried out an exhaustive study on the heat treatment of SLM printed Ti-6Al-4V and was able to obtain maximum ductility of $12.84 \pm 1.36 \%$ compared to $7.36 \pm 1.32 \%$ for as-built parts. Cao et al. [36] reported the static coarsening mechanism of selective laser melted Ti-6Al-4V with a lamellar microstructure.

Titanium does not have a widespread use in the commercial nuclear industry (i.e., commercial power plants) due to its moderate neutron capture cross section. However, it is used in specialty nuclear research application, as it does not transmute into long-lived radioactive isotopes. In fact, $\mathrm{Ti}, \mathrm{Al}$, and $\mathrm{V}$ are three of the very best metals for this purpose. The purpose of this study was to correlate the quasi-static, tensile mechanical behavior of Ti-6Al-4V ELI alloy to the phase constituents and microstructure that changed after post-heat treatment of stress relief and HIP. Laser powder bed fusion (LPBF) technique was employed to build Ti-6Al-4V ELI alloy tensile specimens in both the horizontal (i.e., $X$ and $Y$ ) and vertical $(Z)$ directions with respect to the build direction (Z). Findings from phase constituent quantification, microstructural analysis, and fracture surface examination were correlated to the difference in mechanical behavior observed for the as-stress-relieved (ASR) and HIP Ti-6Al-4V ELI alloy specimens built in X, Y, and Z directions. Furthermore, to examine the coarsening behavior of the $\alpha+\beta$ microstructure, which may be of interest to better explore the HIP process, heat treatment was carried out for the Ti-6Al-4V ELI alloy specimens below the $\beta$ transus temperatures to document the microstructure coarsening kinetics as functions of temperature and time.

\section{Experimental Details}

\subsection{Materials and Samples}

As-stress relieved (ASR) and hot isostatically pressed (HIP) Ti-6Al-4V ELI alloy tensile specimens were produced by using OEM recommended LPBF parameters on 3D Systems ProX DMP 320 (3D Systems, Rockhill, SC, USA) with LaserForm ${ }^{\circledR}$ Ti-6Al-4V ELI (Grade 23) powders (3D Systems, Rockhill, SC, USA). This instrument has a build platform of $275 \mathrm{~mm} \times 275 \mathrm{~mm} \times 420 \mathrm{~mm}$, and is equipped with a continuous laser with a maximum power of $500 \mathrm{~W}, 1070 \mathrm{~nm}$ in wavelength, and $70 \mu \mathrm{m}$ in beam size. Commercially, two types of powders can be used for the AM of Ti-6Al-4V alloy components: grade $23 \mathrm{Ti}-6 \mathrm{Al}-4 \mathrm{~V}$ extra low interstitial (ELI) and grade $5 \mathrm{Ti}-6 \mathrm{Al}-4 \mathrm{~V}$, which differ in the reduction of oxygen 
content to $0.13 \%$ (maximum) in grade 23 . This reduction in oxygen content in Ti-6Al-4V ELI (grade 23) powder provides an improvement in ductility and fracture toughness, however, with a minor reduction in strength [37]. LaserForm ${ }^{\circledR}$ Ti-6Al-4V ELI (Grade 23) is an extra low interstitial grade with lower iron, carbon, and oxygen content, and is known for a higher purity that yields consistent strength, ductility, and fracture toughness [37]. There were nine ASR and nine HIP specimens, built both in the horizontal ( 3 in $X$ and 3 in $Y$ ) and vertical ( 3 in $Z$ ) directions with respect to the build direction $(Z)$. Laser power of $270 \mathrm{~W}$, scan speed of $1800 \mathrm{~mm} / \mathrm{s}$, slice thickness of $30 \mu \mathrm{m}$, and hatch spacing of $85 \mu \mathrm{m}$, as per the recommended parameters, were employed. The samples were $160 \mathrm{~mm}$ long, and had diameters of $8 \mathrm{~mm}$ and $14 \mathrm{~mm}$ through the gauge and grip sections, respectively. The gauge section was $60 \mathrm{~mm}$. These were identified as sample series A, B, and C respectively, as listed in Table 1.

Table 1. Sample identification employed in this study.

\begin{tabular}{cccc}
\hline \multirow{2}{*}{ Sample } & \multicolumn{3}{c}{ Build Direction } \\
\cline { 2 - 4 } & Horizontal-X & Horizontal-Y & Vertical-Z \\
\hline \multirow{2}{*}{ As stress relieved } & ASR-A1 & ASR-B1 & ASR-C1 \\
(ASR) & ASR-A2 & ASR-B2 & ASR-C2 \\
& ASR-A3 & ASR-B3 & ASR-C3 \\
\hline \multirow{2}{*}{ Hot isostatically } & HIP-A1 & HIP-B1 & HIP-C1 \\
pressed (HIP) & HIP-A2 & HIP-B2 & HIP-C2 \\
& HIP-A3 & HIP-B3 & HIP-C3 \\
\hline
\end{tabular}

The ASR Ti-6Al-4V ELI samples underwent stress relief heat treatment, which consisted of heat treatment at $670{ }^{\circ} \mathrm{C}$ for $5 \mathrm{~h}$ followed by furnace cooling. HIP was performed at $920^{\circ} \mathrm{C}$ for $2 \mathrm{~h}$ with a gas pressure of $100 \mathrm{MPa}$, followed by controlled air cooling from $920{ }^{\circ} \mathrm{C}$ to $150{ }^{\circ} \mathrm{C}$ in $12 \mathrm{~h}$ with an estimated cooling rate of $0.02{ }^{\circ} \mathrm{C} / \mathrm{s}$. All heat treatments were performed while the components were attached to the build platform.

\subsection{Mechanical Testing and Heat Treatment}

Tensile properties were determined for the samples produced with optimum LPBF parameters. Minor mechanical machining was carried out so that the tensile testing could be performed with digital image correlation (DIC) (e.g., painted optically smooth surface) and in accordance with the ASTM E8/E8M standards. Each sample tested had a gauge length and diameter of $60 \mathrm{~mm}$ and $8 \mathrm{~mm}$, respectively. The total length and diameter of the sample were $160 \mathrm{~mm}$ and $14 \mathrm{~mm}$, respectively. Room temperature uniaxial tensile tests were carried out quasi-statically using a MTS universal testing that had a $110 \mathrm{kN}$ frame with a $110 \mathrm{kN}$ load cell. The tensile loading rate of $0.01 \mathrm{~mm} / \mathrm{s}$ was used. A quasi-static strain rate of $4 \times 10^{-4} \mathrm{~s}^{-1}$ was applied for all tests. All deformations were recorded and measured by the DIC technique. The system consists of a Tokina AT-X Pro macro $100 \mathrm{~mm}$ $\mathrm{f} / 2.8-\mathrm{d}$ lens (Tokyo, Japan) with a resolution of $2448 \times 2048$ and VIC-2D 2009 software by Correlated Solutions, Inc. (Irmo, SC, USA). One DIC camera placed perpendicular to the specimen plane was used for all tests. The capture frequency was $1 \mathrm{~Hz}$. Engineering stress-strain curves were obtained with a MTS machine force with a virtual extensometer through DIC analysis.

The hardness of the ASR and HIP samples was measured using a Leco (St. Joseph, MI, USA) LV700TM Vickers hardness tester with a load of $10 \mathrm{kgf}$ and a dwell time of $10 \mathrm{~s}$. All samples were polished down to $1 \mu \mathrm{m}$ surface finish before the hardness measurement. Five measurements were performed on each sample for the average and standard deviation.

To investigate the coarsening behavior of the $\alpha+\beta$ microstructure in the HIP Ti-6Al$4 \mathrm{~V}$ ELI alloy samples, heat treatment was carried out below the $\beta$ transus temperature $\left(\sim 1000^{\circ} \mathrm{C}\right)$. The starting $\alpha+\beta$ microstructure found in HIP samples built in the $X$ direction (HIP-A series) was heat treated at 920,950 , and $970{ }^{\circ} \mathrm{C}$ as a function of time (i.e., 2, 5, 20, 100 , and 200 h), followed by air cooling. For heat treatment, sectioned samples (discs with a 
diameter of $14 \mathrm{~mm}$ and height of $6 \mathrm{~mm}$ approximately) were encapsulated in a quartz tube and purged with ultra-high purity (UHP) Ar and $\mathrm{H}_{2}$ (five times each) until a vacuum of $10^{-6}$ torr was achieved. The quartz tube was eventually backfilled with UHP Ar to impart $1 \mathrm{~atm}$ pressure at elevated temperature before sealing with an oxy-acetylene torch. Based on the optical micrographs, lamellar width (20 readings for each sample) was quantified by ImageJ (National Institute of Health) image analysis software. The process was repeated on three optical micrographs and the average lamellar width was determined based on 60 measurements per sample.

\subsection{Microstructural Characterization}

Sample densities were determined first by the Archimedes method and image analysis prior to detailed microstructural characterization. The Ti-6Al-4V ELI alloy samples were sectioned by a diamond sectioning saw into $X Z, Y Z$, and $X Y$ cross sections. Each sample sectioned was mounted in epoxy and prepared metallographically by grinding and polishing. The unetched optical micrographs were examined and analyzed with the ImageJ software to determine the number of pores/flaws. Keller's reagent was then used to observe the cross-sectional phase constituents and microstructure by a Nikon Metaphot optical microscope.

X-ray diffraction (XRD) was carried out for phase identification and preferred crystallographic orientation analysis using a PANalytical Empyrean ${ }^{\mathrm{TM}}$ diffractometer with $\mathrm{Cu}$ target $\mathrm{K} \alpha$ radiation operating at $45 \mathrm{kV}$ and $40 \mathrm{~mA}$. A step size of $0.03^{\circ}$ and a counting duration of $90 \mathrm{~s}$ were employed for good resolution and statistical significance. Quantitative phase analysis of the XRD data was performed using Rietveld refinement within Malvern Panalytical (Westborough, MA, USA) HighScore Plus software (version 4.1). The parameters required to run the Rietveld refinement for the Ti-6Al-4V ELI alloy were taken from the published crystallographic data from Springer Materials available online [38]. Corresponding weighted $R_{\text {profile }}\left(R_{\mathrm{wp}}\right)$ and goodness of fit (GOF) were checked consistently after every execution of fit. Typically, in a good fit, $R_{\mathrm{wp}}$ should be less than $10 \%$ and GOF should be less than 4 [39] for consistent Rietveld refinement results.

Field emission scanning electron microscope (FE-SEM, Zeiss Ultra-55TM; Zeiss USA, White Plains, NY, USA) equipped with X-ray energy dispersive spectroscopy (XEDS) was used to examine the fracture surface morphology, cross-sectional phase constituents, and microstructure. Detailed microstructure and crystal structure of phases present were investigated by using a transmission electron microscope (TEM, FEI/Tecnai F30; Thermo Fisher Scientific, Hillsboro, OR, USA) equipped with an XEDS. In situ lift out (INLO) technique was employed to obtain site-specific TEM thin foils by using a focused ion beam (FIB, FEI TEM200; Thermo Fisher Scientific, Hillsboro, OR, USA).

\section{Results and Analysis}

\subsection{Visual Examination of Specimens after Tensile Testing}

Figure 1 presents the macro photographs of the ASR and HIP Ti-6Al-4V ELI tensile specimens after fracture. Inconsistency in the location of fracture, although all within the gauge length, was observed. In particular, for the vertically built ASR samples (ASR-C1, ASR-C2, and ASR-C3), the fracture occurred away from the middle of the gauge section. On the other hand, the HIP samples fractured consistently within the middle of the gauge section, as shown in Figure 1. A close examination of these photographs also demonstrates that the HIP samples fractured after necking, while this type of plastic deformation was not visible for the ASR samples. 

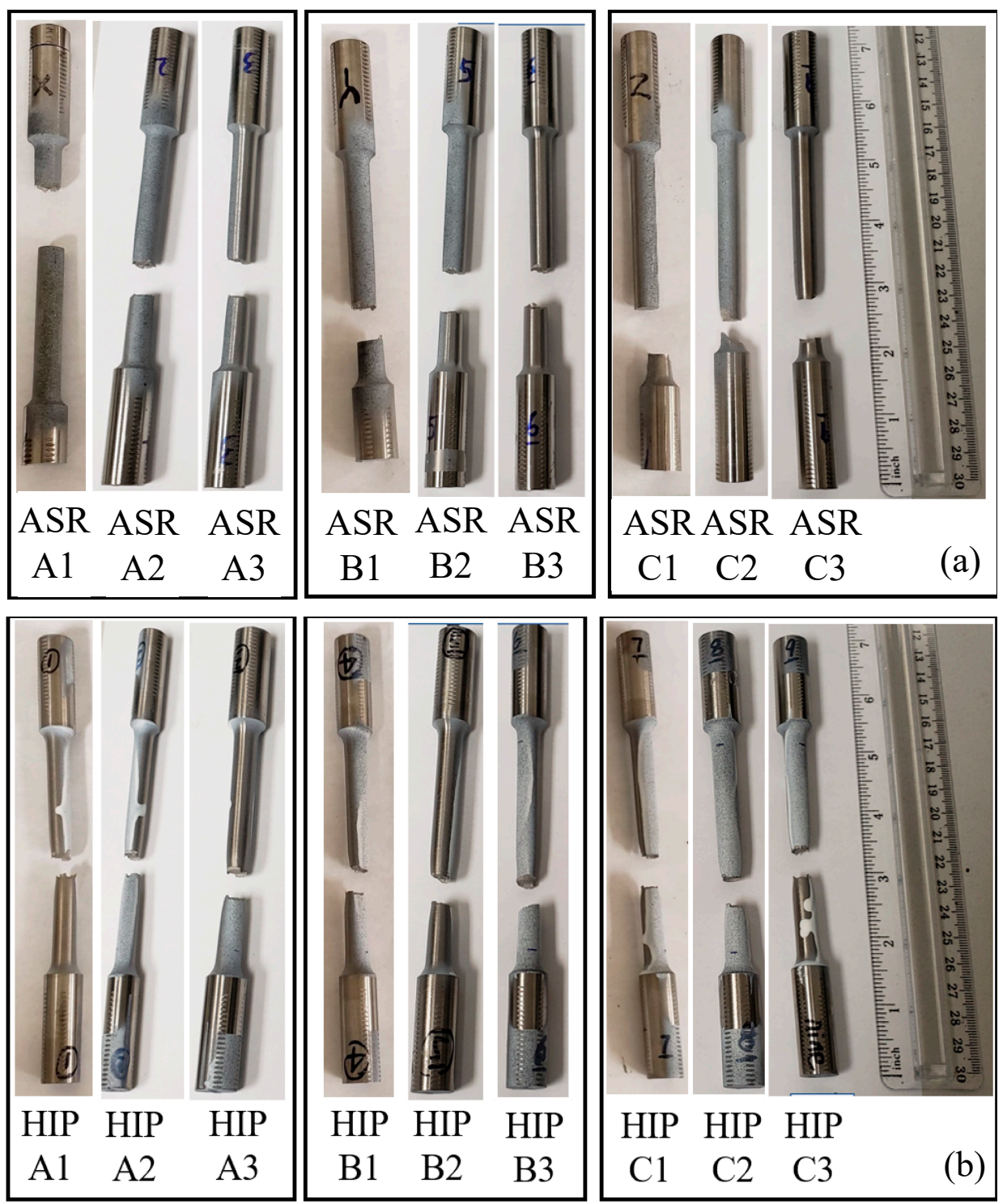

Figure 1. Fractured tensile specimens: (a) as-stress relieved (ASR) and (b) hot isostatically pressed (HIP) Ti-6Al-4V ELI alloy. Sample series A and B were horizontally built in X and Y direction, while $\mathrm{C}$ was built vertically in the $\mathrm{Z}$ direction, which is the build direction of the LPBF. Note that minor size variation is due to the photography and not the sample size.

\subsection{Mechanical Properties}

The engineering stress-strain data obtained from all ASR and HIP samples are presented in Figure 2. Yield strength (YS), ultimate tensile strength (UTS), Young's modulus, and $\%$ elongation at fracture were determined from the engineering stress-strain data as presented in Tables 2 and 3, respectively, for the ASR and HIP samples. The ASR samples built in the horizontal directions, $\mathrm{X}$ and $\mathrm{Y}$, identified as sample series $\mathrm{A}$ and $\mathrm{B}$, had an average yield strength of $1111.74 \mathrm{MPa}$ and $1146.70 \mathrm{MPa}$, respectively. The samples built in the vertical direction, $Z$, identified by sample series $C$, had an average yield strength of $1163.45 \mathrm{MPa}$. The ASR sample series A and B, respectively, had an average tensile strength of $1169.66 \mathrm{MPa}$ and $1206.98 \mathrm{MPa}$, while for sample series C, it was $1192.82 \mathrm{MPa}$. The \% elongation at fracture for the ASR samples A and B were $9.20 \%$ and $7.88 \%$, respectively, however, it was only $3.81 \%$ for sample series C. 

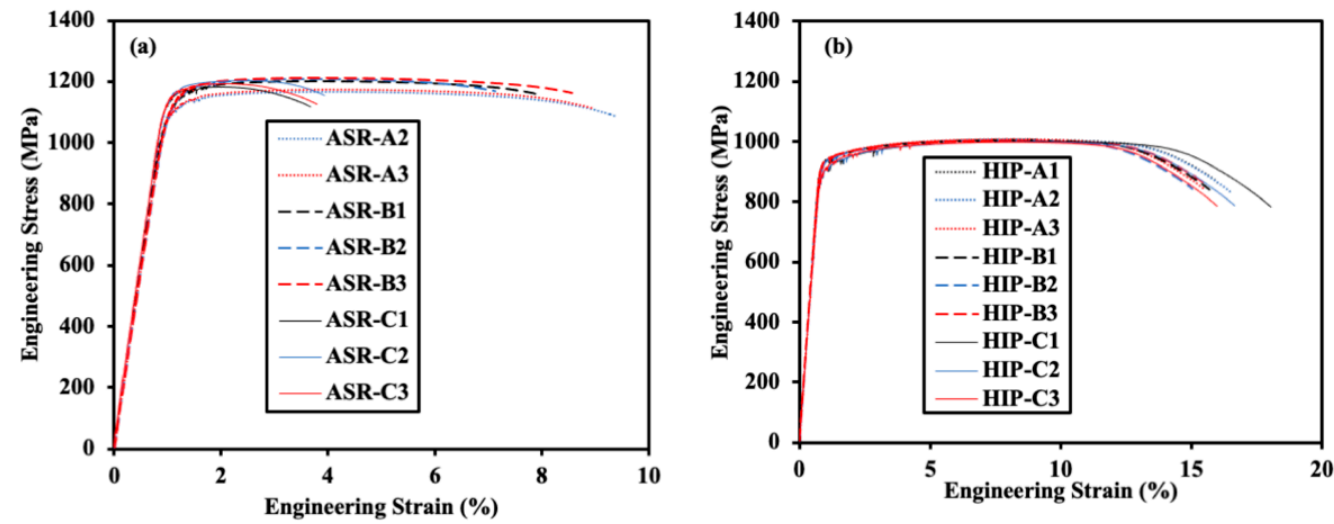

Figure 2. Engineering stress-strain curves obtained from all the Ti-6Al-4V ELI tensile samples: (a) as-stress relieved (ASR) and (b) hot isostatically pressed (HIP).

Table 2. Tensile properties determined from the as-stress relieved (ASR) Ti-6Al-4V ELI alloy samples.

\begin{tabular}{|c|c|c|c|c|}
\hline Sample & $\begin{array}{l}Y S, \sigma_{0.2 \%} \\
\text { (MPa) }\end{array}$ & $\begin{array}{l}\text { UTS } \\
\text { (MPa) }\end{array}$ & $\begin{array}{c}\% \\
E L \text { at Fracture }\end{array}$ & $\begin{array}{c}\text { Young's Modulus } \\
\text { (GPa) }\end{array}$ \\
\hline ASR-A2 & 1107.52 & 1164.61 & 9.40 & 115.75 \\
\hline ASR-A3 & 1115.96 & 1175.71 & 9.00 & 115.00 \\
\hline $\begin{array}{l}\text { Average and Standard } \\
\text { deviation for ASR-A }\end{array}$ & $1111.74 \pm 4.22$ & $1169.66 \pm 5.05$ & $9.20 \pm 0.20$ & $115.88 \pm 0.13$ \\
\hline ASR-B1 & 1137.38 & 1200.47 & 7.95 & 116.18 \\
\hline ASR-B2 & 1149.13 & 1209.02 & 7.13 & 113.68 \\
\hline ASR-B3 & 1153.60 & 1211.45 & 8.57 & 113.38 \\
\hline $\begin{array}{l}\text { Average and Standard } \\
\text { deviation for ASR-B }\end{array}$ & $1146.70 \pm 6.84$ & $1206.98 \pm 4.71$ & $7.88 \pm 0.59$ & $114.75 \pm 1.05$ \\
\hline ASR-C1 & 1157.11 & 1182.57 & 3.68 & 121.53 \\
\hline ASR-C2 & 1169.93 & 1203.25 & 3.95 & 120.23 \\
\hline ASR-C3 & 1163.30 & 1192.64 & 3.80 & 121.62 \\
\hline $\begin{array}{l}\text { Average and Standard } \\
\text { deviation for ASR-C }\end{array}$ & $1163.45 \pm 5.23$ & $1192.82 \pm 8.44$ & $3.81 \pm 0.11$ & $121.13 \pm 0.64$ \\
\hline
\end{tabular}

Table 3. Tensile properties determined from the hot isostatically pressed (HIP) Ti-6Al-4V ELI alloy samples.

\begin{tabular}{|c|c|c|c|c|}
\hline Sample & $\begin{array}{l}Y S_{,} \sigma_{0.2} \% \\
(\mathrm{MPa})\end{array}$ & $\begin{array}{l}\text { UTS } \\
(\mathrm{MPa})\end{array}$ & $\begin{array}{c}\% \\
E L \text { at Fracture }\end{array}$ & $\begin{array}{l}\text { Young's Modulus } \\
\text { (GPa) }\end{array}$ \\
\hline HIP-A1 & 937.40 & 1006.94 & 16.05 & 115.87 \\
\hline HIP-A2 & 936.69 & 1006.33 & 16.55 & 115.36 \\
\hline HIP-A3 & 936.08 & 1007.57 & 15.49 & 115.34 \\
\hline $\begin{array}{l}\text { Average and Standard } \\
\text { deviation for HIP-A }\end{array}$ & $936.72 \pm 0.54$ & $1006.94 \pm 0.51$ & $16.03 \pm 0.43$ & $115.5 \pm 0.25$ \\
\hline HIP-B1 & 933.55 & 1003.55 & 15.68 & 118.60 \\
\hline HIP-B2 & 933.80 & 1003.82 & 15.02 & 114.15 \\
\hline HIP-B3 & 939.09 & 1002.50 & 15.44 & 117.88 \\
\hline $\begin{array}{l}\text { Average and Standard } \\
\text { deviation for HIP-B }\end{array}$ & $935.48 \pm 2.55$ & $1003.29 \pm 0.57$ & $15.38 \pm 0.27$ & $116.88 \pm 1.95$ \\
\hline HIP-C1 & 907.72 & 1000.27 & 18.03 & 112.98 \\
\hline HIP-C2 & 908.70 & 998.85 & 16.64 & 113.32 \\
\hline HIP-C3 & 915.68 & 997.67 & 15.97 & 112.97 \\
\hline $\begin{array}{l}\text { Average and Standard } \\
\text { deviation for HIP-C }\end{array}$ & $910.70 \pm 3.54$ & $998.93 \pm 1.06$ & $16.88 \pm 0.86$ & $113.09 \pm 0.16$ \\
\hline
\end{tabular}


The horizontally built HIP samples in the $\mathrm{X}$ and $\mathrm{Y}$ directions (sample series $\mathrm{A}$ and $\mathrm{B}$, respectively) had an average yield strength of $936.72 \mathrm{MPa}$ and $935.48 \mathrm{MPa}$, respectively, while the $C$ samples series vertically built in the $Z$ direction had an average yield strength of $910.70 \mathrm{MPa}$. The horizontally built samples had an average tensile strength of 1006.94 MPa and 1003.29 MPa, respectively, for the HIP-A and HIP-B series. For sample series $\mathrm{C}$ built vertically, the tensile strength was $998.93 \mathrm{MPa}$ after HIP. More importantly, the $\%$ elongation at fracture for samples series A, B and C were $16.03 \%, 15.38 \%$, and $16.88 \%$ respectively. The yield strength, tensile strength, \% elongation at fracture, and Young's modulus showed isotropic and consistent mechanical properties, regardless of the build directions after HIP treatment.

To clearly recognize the difference in mechanical behavior of the ASR and HIP samples, each built in the X, Y, and Z-directions, the modulus of toughness (MOT; integrated area under the engineering stress-strain curve, frequently referred to as toughness) was determined, as presented in Figure 3a. The ASR samples, in general, had lower MOTs than the HIP samples. In addition, a significant anisotropic behavior was observed since the C-series samples, built along the build direction $\mathrm{Z}$, had a MOT of only $39 \mathrm{~J} / \mathrm{m}^{3}$ while the A- and B-series ASR samples, built in the $\mathrm{X}$ and $\mathrm{Y}$ directions, yielded the MOT values of 100 and $88 \mathrm{~J} / \mathrm{m}^{3}$, respectively. However, more importantly, after the HIP, the MOTs for all samples were quite consistent and isotropic, ranging from 146 to $159 \mathrm{~J} / \mathrm{m}^{3}$.
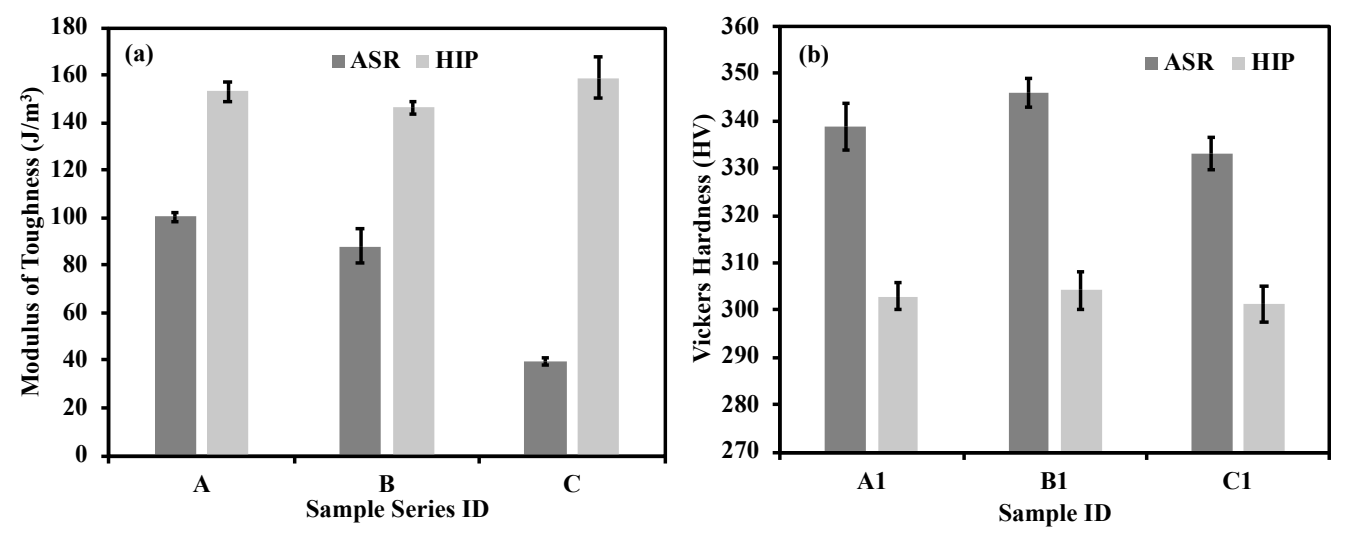

Figure 3. (a) Modulus of toughness and (b) Vickers hardness determined for the as stress-relieved (ASR) and hot-isostatically pressed (HIP) Ti-6Al-4V ELI alloy samples. Uncertainty in (a) was determined from stress-strain curves (average and standard deviation from area under the curve). Standard deviation from (b) was determined from five measurements from random locations.

Vickers hardness of the ASR and HIP samples were determined from the XZ, YZ, and $X Y$ cross sections, as reported in Figure 3b. The ASR samples in general had higher hardness than the HIP samples. The ASR samples, however, showed some variation in the hardness ranging from $333 \mathrm{HV}$ to $346 \mathrm{HV}$. After HIP, however, the hardness for all samples was quite consistent and isotropic, ranging from 301 to $304 \mathrm{HV}$.

Archimedes and image analysis methods were used to determine the relative density, as reported in Table 4 . Density of all samples was greater than $99 \%$. Some fine pores/flaws were occasionally observed in the unetched optical micrographs, but were rarely observed in the HIP samples. However, statistically confident analysis to distinguish the number of pores/flaws was challenging to carry out given the high density achieved by the use of optimized LPBF parameters. 
Table 4. Density of the ASR and HIP Ti-6Al-4V ELI alloy samples.

\begin{tabular}{ccc}
\hline Sample ID & Density by Image Analysis (\%) & Archimedes Density (\%) \\
\hline ASR-A1 & $99.97 \pm 0.01$ & $99.37 \pm 0.03$ \\
ASR-B1 & $99.96 \pm 0.01$ & $99.60 \pm 0.05$ \\
ASR-C1 & $99.95 \pm 0.01$ & $99.54 \pm 0.05$ \\
HIP-A1 & $99.99 \pm 0.01$ & $99.22 \pm 0.06$ \\
HIP-B1 & $99.99 \pm 0.01$ & $99.05 \pm 0.09$ \\
HIP-C1 & $99.98 \pm 0.02$ & $99.19 \pm 0.07$ \\
\hline
\end{tabular}

\subsection{Fracture Surface Features}

Secondary electron micrographs in Figure 4 show the representative details of the fracture surfaces for the horizontally and vertically built Ti-6Al-4V ELI alloy samples. These micrographs were obtained from the fractured samples: (a) ASR-A1, (b) HIP-A1, (c) ASR-B1, (d) HIP-B1, (e) ASR-C1, and (f) HIP-C1. In general, the fracture surfaces of the ASR samples presented in Figure 4a,c,e, exhibited mixed modes of ductile and brittle failure modes, while those of the HIP samples exhibited more dimples associated with ductile fracture, as shown in Figure $4 b, d, f$. This ductile fracture corresponds well with the mechanical properties of the HIP samples as both the horizontally (identified as sample series A and B) and vertically built samples (sample series $C$ ) exhibited isotropic and consistent elongation at fracture of $16.03 \%, 15.38 \%$, and $16.88 \%$. The fracture surfaces of the ASR samples showed fewer dimples compared to the HIP samples, and exhibited some quasi-cleavage facets closely associated with the mixed mode of ductile and brittle failure $[2,7,40]$. Hence, horizontally built ASR samples (ASR-A and ASR-B) had an elongation at fracture of $9.20 \%$ and $7.88 \%$, while vertically built ASR-C samples only had an elongation at fracture of 3.81\%.
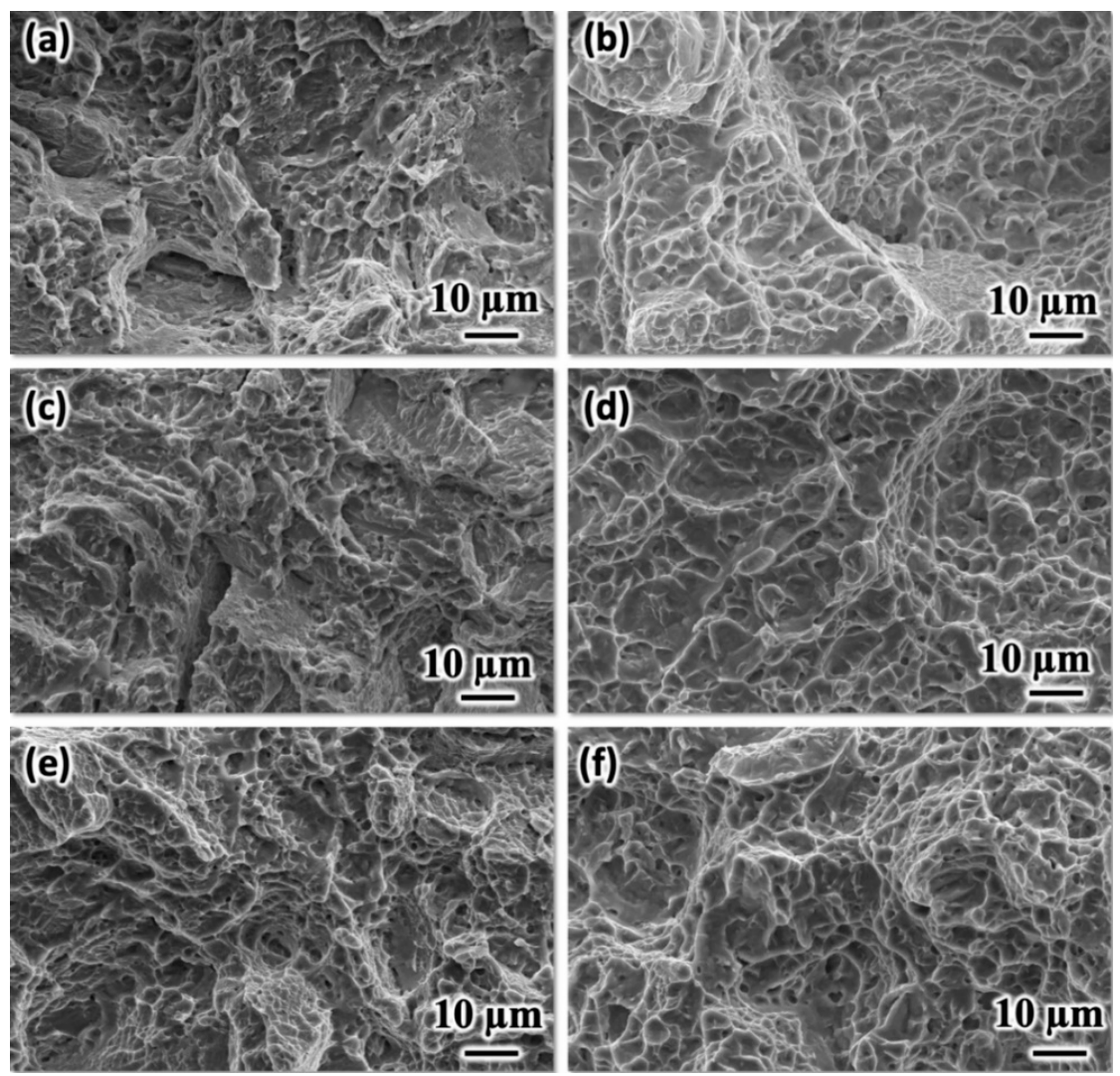

Figure 4. Secondary electron fractographic micrographs at higher magnification for Ti-6Al-4V ELI alloy samples after ASR and HIP: (a) ASR-A1, (b) HIP-A1, (c) ASR-B1, (d) HIP-B1, (e) ASR-C1, and (f) HIP-C1. 
One noticeable feature on the ASR-C1 sample, which was built along the Z direction (i.e., the build direction) and exhibited the lowest ductility and MOT of $3.60 \%$ and $39 \mathrm{~J} / \mathrm{m}^{3}$, respectively, was the large pockets, as presented in Figure 5. The size of these pockets ranged from 30 to $100 \mu \mathrm{m}$, and corresponded well to the reported "keyhole" pores typically observed in LPBF. These would appear frequently on the fracture surface because they act as a stress-concentration point/area during tensile testing. The surface of these pores were mostly smooth, and some dendritic features were observed.
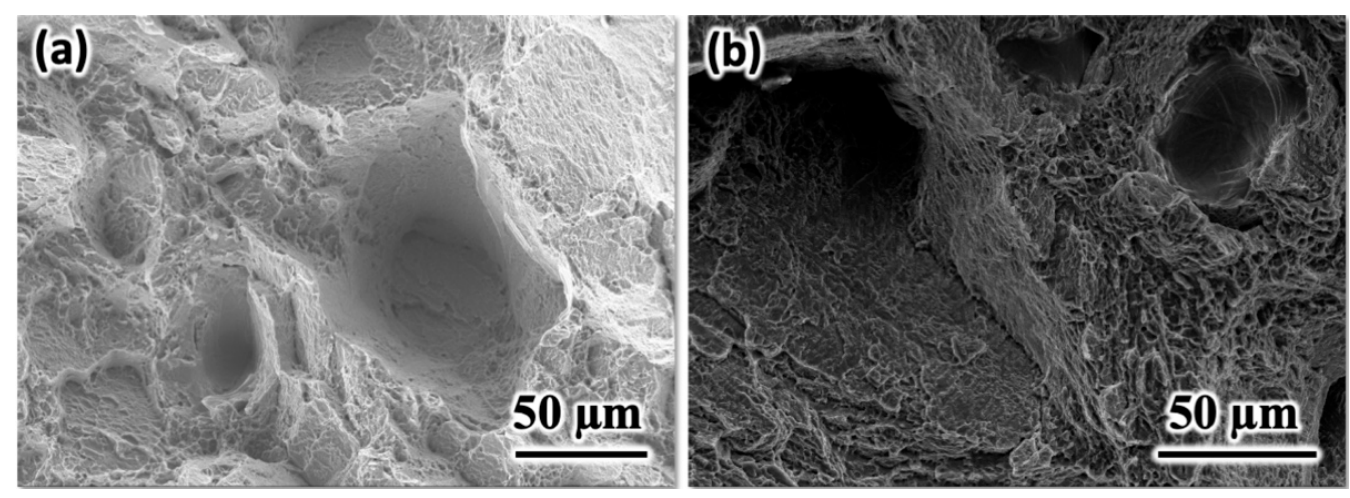

Figure 5. Secondary electron fractographic micrographs demonstrating the presence of large pockets in the $(\mathbf{a}, \mathbf{b})$ vertically built ASR-C1, Ti-6Al-4V ELI alloy sample.

\subsection{Phase Constituents and Microstructure}

Representative XRD patterns collected from the XZ cross-section of ASR and HIP samples are presented in Figure 6. The main peaks observed from the ASR and HIP samples were from the $\alpha^{\prime}$ (hcp) phase and $\alpha$ (hcp) phases, respectively. In addition, a very small peak at $2 \theta=39.47^{\circ}$ was observed for the HIP samples only, which corresponded to the presence of the $\beta$ phase [32]. All peaks were indexed by comparing with the International Center for Diffraction Data (ICDD) powder diffraction files through the PANalytical HighScore software (01-089-5009). The presence of the $\alpha^{\prime}$ phase in the ASR samples and $\alpha$ phase in the HIP samples was confirmed by the refined X-ray diffraction pattern using the Rietveld fit, which yielded the $\alpha^{\prime}$ and $\alpha$ phase with the hexagonal lattice of $a=2.94 \AA$ and $c=4.68 \AA$, identical to the reported values of $\alpha^{\prime}$ in the literature [41] and space group of $\mathrm{P} 6_{3} / \mathrm{mmc}$ (194). This is primarily due to the fact that XRD cannot differentiate between the $\alpha^{\prime}$ and $\alpha$ phases as they have the same hcp crystal structure and very similar lattice parameters [42].

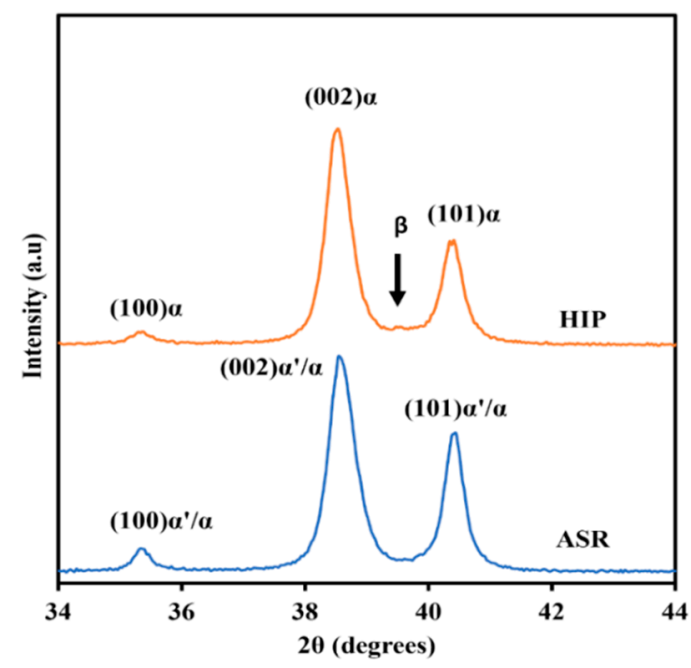

Figure 6. Representative X-ray diffraction patterns of the ASR and HIP Ti-6Al-4V ELI alloy samples. 
The Rietveld fit of the HIP samples also revealed the presence of the $\beta$ phase with the bcc lattice parameter of $a=3.23 \AA$, slightly higher than the 3.18-3.21 $\mathrm{A}$ reported in the literature [19,43], and space group of $\operatorname{Im} \overline{3} \mathrm{~m}$ (229). The presence of $\alpha$ and $\beta$ phases, confirmed by the Rietveld refinement, indicates that the $\alpha^{\prime} \rightarrow \alpha+\beta$ phase transformation occurred during the HIP of the ASR samples. Finally, quantitative phase analysis was performed for the XRD patterns using Rietveld refinement, which resulted in $100 \% \alpha^{\prime}$ for the ASR sample and $89.30 \mathrm{wt} . \% \alpha$ and $10.70 \mathrm{wt} . \% \beta$ for the HIP-A1 sample. Similarly, quantitative phase analysis performed for the XRD patterns using Rietveld refinement for the HIP-B1 and HIP-C1 samples resulted in $90.80 \mathrm{wt} . \% \alpha$ and $9.20 \mathrm{wt} . \% \beta$ (GOF: $2.09 \%$ ) and $89.10 \mathrm{wt} . \% \alpha$ and $10.90 \mathrm{wt} . \% \beta$ (GOF: $2.42 \%$ ). The relevant parameters obtained from the Rietveld refinement are presented in Table 5.

Table 5. Parameters for the Rietveld refinement of XRD patterns from the ASR ( $\alpha^{\prime}$ phase) and HIP $(\alpha+\beta$ phases) Ti-6Al-4V ELI alloy samples.

\begin{tabular}{cccc}
\hline Parameters & $\boldsymbol{\alpha}^{\prime}$ Phase & $\alpha$ Phase & $\beta$ Phase \\
\hline ICDD database code & $01-089-5009$ & $01-089-5009$ & $01-081-9813$ \\
ICSD database code & 76,265 & 76,265 & 187,067 \\
Volume percent & 100 & 98.59 & 1.41 \\
Weight per cent & 100 & 89.30 & 10.70 \\
Space group (No.) & $\mathrm{P}_{3} / \mathrm{mmc}(194)$ & $\mathrm{P} 6_{3} / \mathrm{mmc}(194)$ & $\operatorname{Im} \overline{3} \mathrm{~m}(229)$ \\
Lattice parameter: $a$ & $2.9440 \AA$ & $2.9440 \AA$ & $3.2322 \AA$ \\
Lattice parameter: $c$ & $4.6780 \AA$ & $4.6780 \AA$ & $3.2322 \AA$ \\
$R$ (weighted profile) & $7.05 \%$ & $8.41 \%$ & $8.41 \%$ \\
Goodness of fit $(G O F)$ & 1.90 & 2.35 & 2.35 \\
\hline
\end{tabular}

ImFigure 7 presents the optical micrographs from the cross-sectional ASR and HIP samples. Samples examined for optical microscopy were prepared from both ends of the tensile rods, but there was no significant variation in the microstructural features and their size. In addition, no significant variation was observed in the $\mathrm{X}, \mathrm{Y}$ and $\mathrm{Z}$ directions within the tensile rods. Due to rapid solidification, followed by the addition of powders in a layer-by-layer approach, the initial microstructures in Ti-6Al-4V fabricated by AM are anisotropic and contain prior $\beta$-grains that grow epitaxially across successive build layers in the laser based additive manufacturing of metals. The microstructure contained within the prior $\beta$-grains differs depending on the cooling rate and thermal cycles. The initial microstructure of the Ti-6Al-4V alloy produced by laser powder bed fusion (PBF) typically tends to be acicular or martensitic $[7,20,23]$.
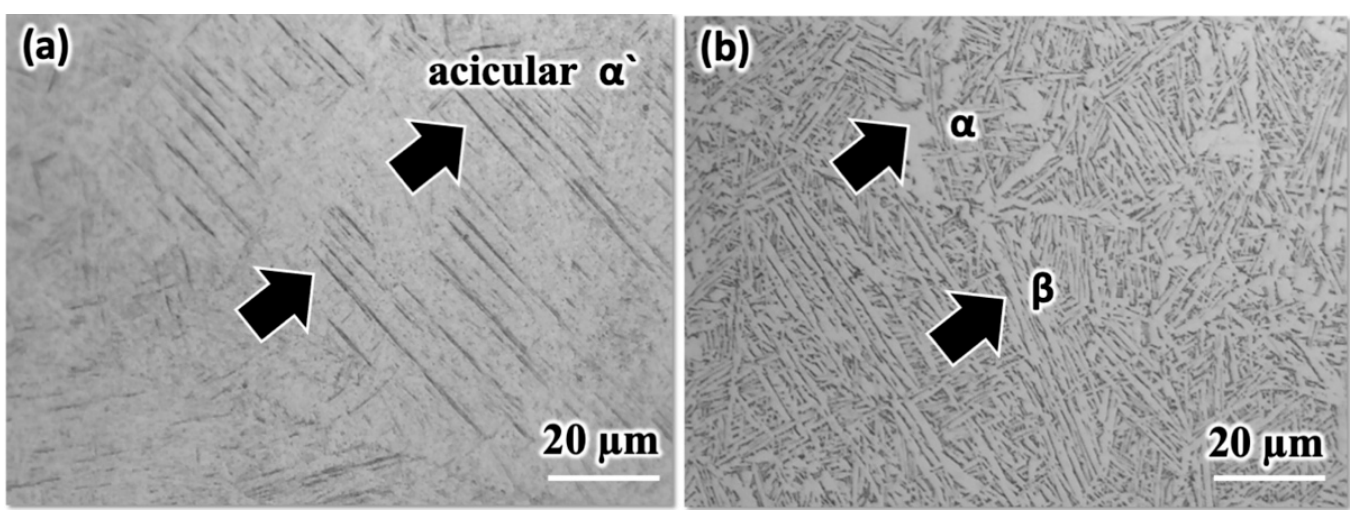

Figure 7. Representative optical micrographs of the Ti-6Al-4V ELI alloy samples: (a) ASR and (b) HIP.

The equilibrium microstructure of the Ti-6Al-4V alloy consists of the $\alpha$ (hcp) and $\beta$ (bcc) phases [44]. Due to the non-equilibrium solidifications inherent to LPBF, the metastable acicular martensitic $\alpha^{\prime}$ (hcp) phase would form after LPBF, and it was experimentally 
observed to remain in the ASR samples that underwent stress-relief heat treatment at $670{ }^{\circ} \mathrm{C}$ for $5 \mathrm{~h}$ followed by furnace cooling, as presented in Figure 7a. These metastable acicular martensitic $\alpha^{\prime}$ phases are considered hard and brittle [45,46], in comparison to the equilibrium mixture of $\alpha$ and $\beta$ phases, and would contribute to the high strength, low ductility, and low MOT observed.

As presented in Figure $7 \mathrm{~b}$, the fine acicular martensitic $\alpha^{\prime}$ phase transformed into the equilibrium lamellar $\alpha+\beta$ mixture after HIP, which was carried at $920{ }^{\circ} \mathrm{C}$ for $2 \mathrm{~h}$ at a pressure of $100 \mathrm{MPa}$ under an Ar atmosphere followed by controlled air cooling. The lighter contrast in Figure $7 \mathrm{~b}$ is the $\alpha$ phase, and the $\beta$ phase appears darker. The phase transformation, $\alpha^{\prime} \rightarrow \alpha+\beta$ corresponded to, as observed in this study, significant increases in ductility, MOT, and isotropy, with a slight decrease in strength.

Figures 8 and 9 present the analytical TEM results for the ASR and HIP samples. The bright field TEM micrographs in Figures 8a and 9a revealed the presence of the acicular $\alpha^{\prime}$ phase in the ASR samples, and the $\alpha$ and $\beta$ lamellae in the HIP samples, respectively. The crystallographic identification of the $\alpha^{\prime}, \alpha$, and $\beta$ phases were carried out with selected area electron diffraction (SAED) [47], and are presented in Figures $8 b$ and $9 b, c$, respectively. The HAADF STEM micrograph of the ASR samples revealed a high density of dislocations while a lamellar $\alpha+\beta$ mixture without significant dislocation density was observed in the HAADF STEM micrograph of the HIP samples.

\subsection{Coarsening during Heat Treatment}

Figure 10 presents the microstructure of HIP Ti-6Al-4V ELI alloy samples before and after the heat treatment at 920,950 , and $970{ }^{\circ} \mathrm{C}$ for a holding time of $200 \mathrm{~h}$ followed by air cooling. The HIP samples used for heat treatment were the HIP samples $\left(920^{\circ} \mathrm{C}\right.$ at $100 \mathrm{MPa}$ for $2 \mathrm{~h}$ under an Ar atmosphere followed by controlled air cooling) that consisted of a lamellar mixture of $\alpha$ and $\beta$ phases. These are the equilibrium phase constituents that would only coarsen at high temperature (i.e., no nucleation kinetics). Coarsening of lamellar width as functions of temperature and time was observed as reported in Table 6. The starting average lamellar width on the HIP sample was around $2.19 \mu \mathrm{m}$, which increased to $8.02 \mu \mathrm{m}$ and $10.83 \mu \mathrm{m}$ after a heat treatment at $920{ }^{\circ} \mathrm{C}$ for $100 \mathrm{~h}$ and $200 \mathrm{~h}$, respectively. This increase in average lamellar width as a function of time was also observed at 950 and $970{ }^{\circ} \mathrm{C}$, as reported in Table 6. Clearly, the most extensive coarsening of the lamellar mixture of $\alpha$ and $\beta$ phases was observed at $970{ }^{\circ} \mathrm{C}$, up to $13.54 \mu \mathrm{m}$ after heat treatment at $970{ }^{\circ} \mathrm{C}$ for $200 \mathrm{~h}$.
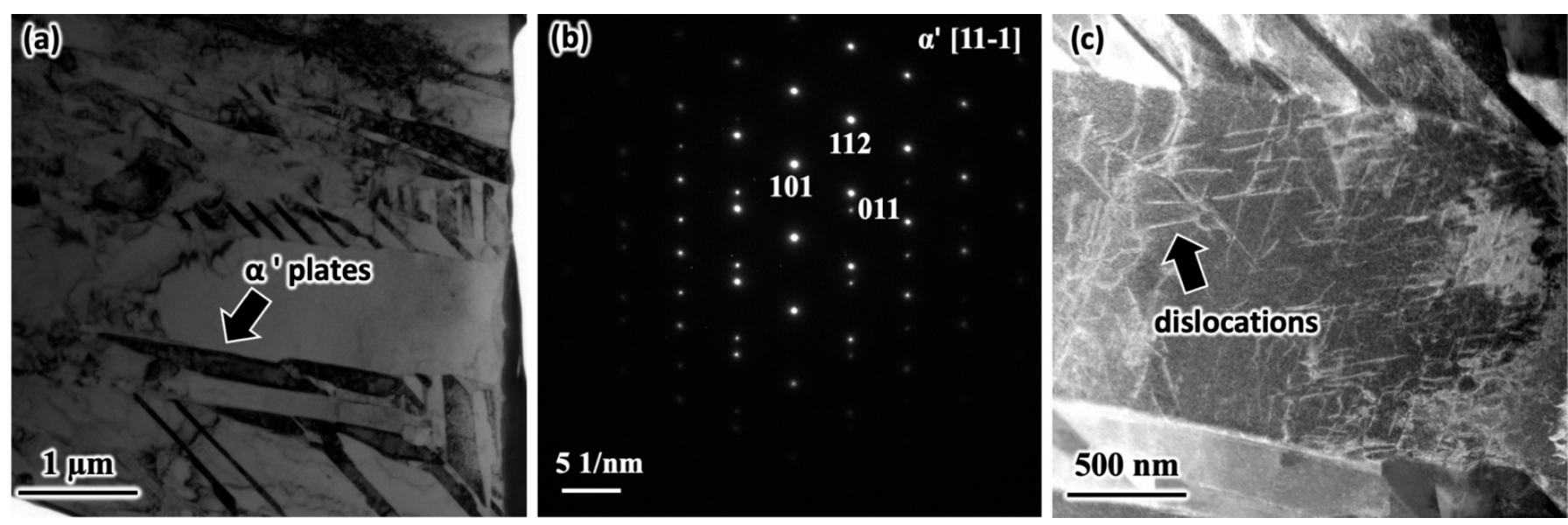

Figure 8. TEM observations from the representative ASR sample: (a) bright field micrograph, (b) SAED pattern from the $\alpha^{\prime}$ phase, and (c) HAADF STEM micrograph. 

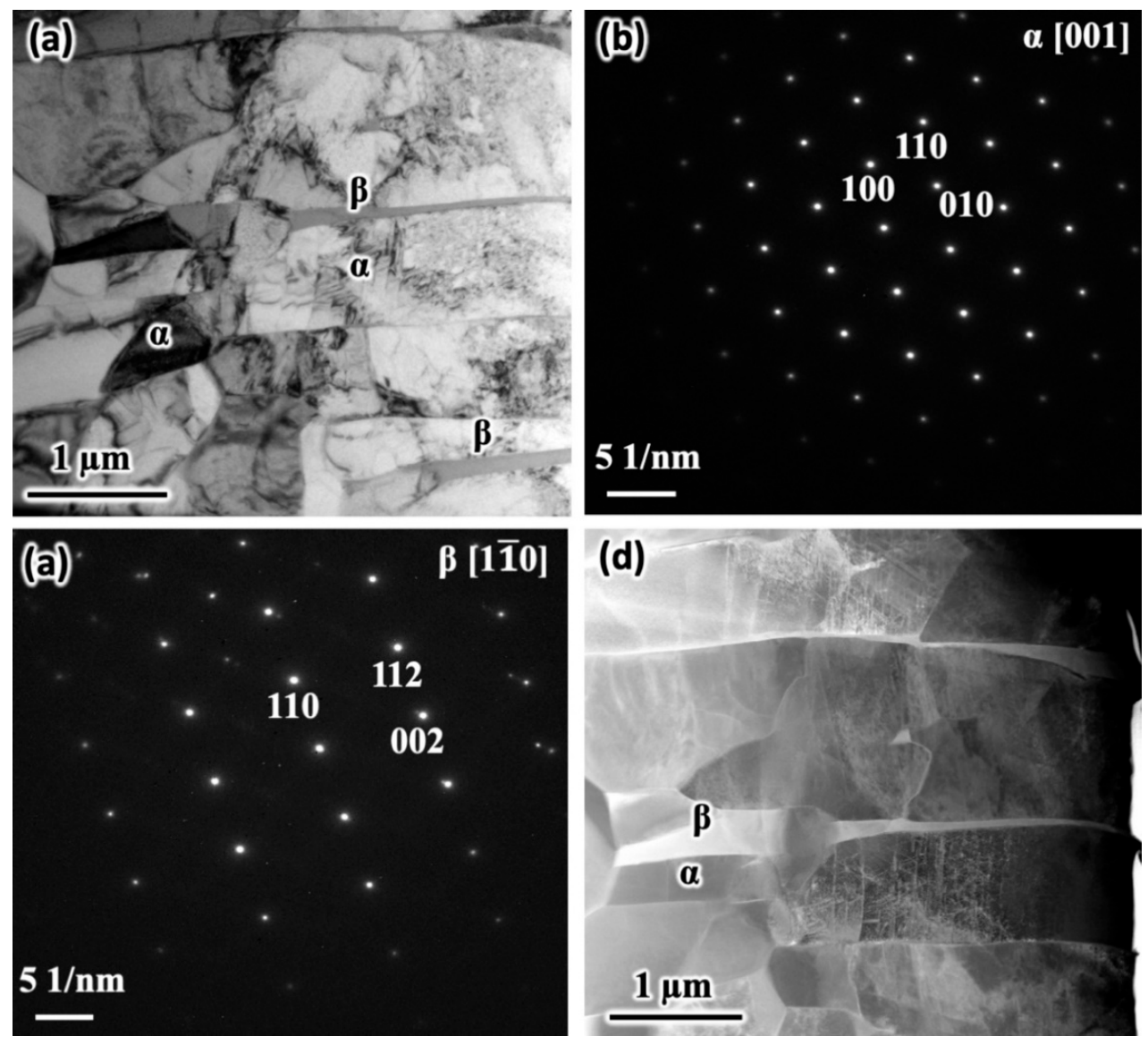

Figure 9. TEM observations from the representative HIP sample: (a) bright field micrograph, (b) SAED pattern from the $\alpha$ phase, (c) SAED from the $\beta$ phase, and (d) HAADF STEM micrograph.
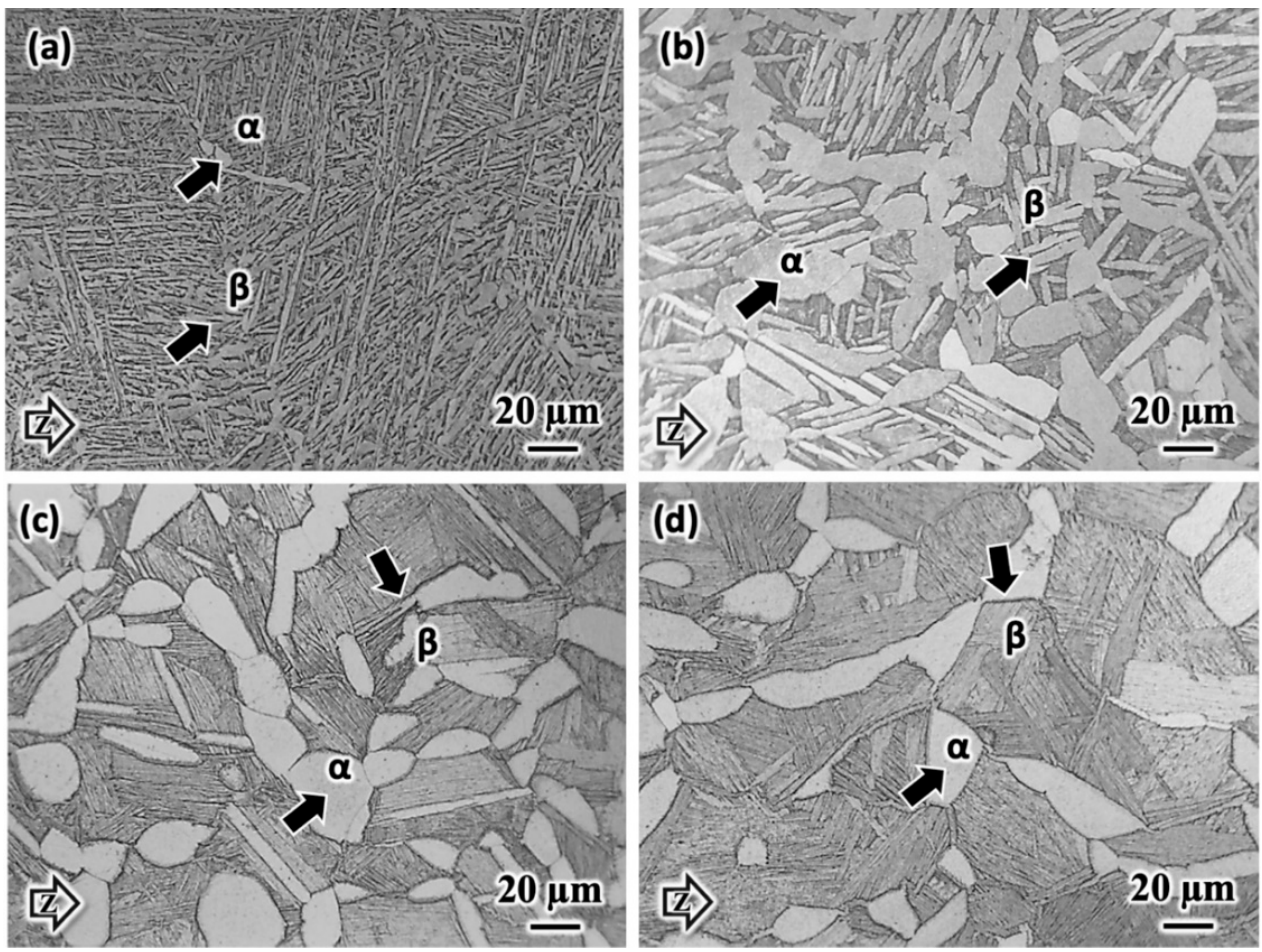

Figure 10. Optical micrographs of the HIP Ti-6Al-4V ELI alloy samples before and after heat treatment, followed by air cooling: (a) before heat treatment, (b) $920^{\circ} \mathrm{C}$ for $200 \mathrm{~h}$, (c) $950^{\circ} \mathrm{C}$ for $200 \mathrm{~h}$, and (d) $970{ }^{\circ} \mathrm{C}$ for $200 \mathrm{~h}$. 
Table 6. Average lamellar width after heat treatment at 920,950 , and $970{ }^{\circ} \mathrm{C}$ as a function of time.

\begin{tabular}{cccc}
\hline \multirow{2}{*}{$\begin{array}{c}\text { Heat Treatment Time } \\
\text { (hours) }\end{array}$} & $\mathbf{9 2 0}{ }^{\circ} \mathbf{C}$ & $\mathbf{9 5 0}{ }^{\circ} \mathbf{C}$ & $\mathbf{9 7 0}{ }^{\circ} \mathbf{C}$ \\
\cline { 2 - 4 } & & Lamellar Width $(\boldsymbol{\mu m})$ \\
\hline 0 & $2.19 \pm 0.55$ & $2.19 \pm 0.55$ & $2.19 \pm 0.55$ \\
$2 \mathrm{~h}$ & $2.74 \pm 0.57$ & $2.95 \pm 0.67$ & $3.45 \pm 0.46$ \\
$5 \mathrm{~h}$ & $3.56 \pm 1.15$ & $3.99 \pm 1.21$ & $4.1 \pm 0.82$ \\
$20 \mathrm{~h}$ & $4.78 \pm 1.32$ & $5.6 \pm 2.41$ & $6.34 \pm 2.31$ \\
$100 \mathrm{~h}$ & $8.02 \pm 3.41$ & $8.88 \pm 4.67$ & $10.99 \pm 3.71$ \\
$200 \mathrm{~h}$ & $10.83 \pm 3.90$ & $12.54 \pm 4.79$ & $13.54 \pm 4.2$ \\
\hline
\end{tabular}

The coarsening theory developed by Lifshitz, Slyozov, and Wagner (LSW) theory [48,49] forms the basis when an infinitesimally small volume fraction of solid phase of essentially pure solute coarsens in a dilute terminal solid solution. Therefore, the LSW theory has been modified, and coarsening kinetics expression predicted by the LSW for the titanium alloy with an $\alpha+\beta$ microstructure can be described by [50]:

$$
\begin{gathered}
d=k t^{n} \\
\text { or } \ln d=\ln k+n \ln t
\end{gathered}
$$

where $d$ is the average lamellar width $(\mu \mathrm{m}) ; k$ is the constant of proportionality; $t$ is the heat treatment time (s); and $n$ is the coarsening coefficient. The experimentally measured lamellar widths $(\mu \mathrm{m})$ and the corresponding heat treatment time $t(\mathrm{~h})$ reported in Table 6 were analyzed with respect to Equations (1) and (2), as presented in Figure 11. The coarsening coefficient $n$ was determined to be $0.29,0.30$, and 0.31 for the temperatures of 920,950 , and $970{ }^{\circ} \mathrm{C}$, respectively. Hence, the process of coarsening appears to be close to lattice diffusion controlled [51]. The values of $\mathrm{k}$ were determined and found to be $6.05 \times 10^{-10}, 6.62 \times 10^{-10}$, and $7.32 \times 10^{-10} \mathrm{~m} / \mathrm{s}$ for 920,950 , and $970{ }^{\circ} \mathrm{C}$, respectively. These coefficients would be valuable for exploring the HIP parameters (i.e., higher temperature and/or longer duration) with prior knowledge of the microstructural features.

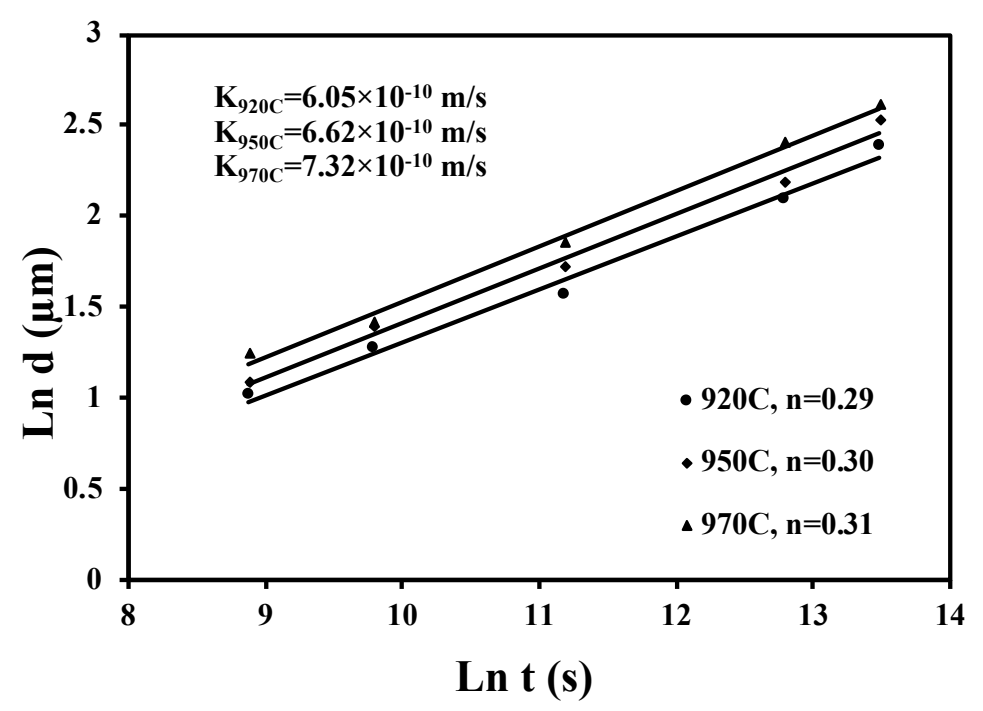

Figure 11. Plots of $\ln d$ vs. $\ln t$ to determine $n$ and $k$ at 920,950 , and $970{ }^{\circ} \mathrm{C}$ for the coarsening of the $\alpha+\beta$ microstructure in the LPBF Ti-6Al-4V ELI alloy.

\section{Discussion}

Due to the rapid cooling rate associated with the LPBF process, the microstructure in the as-built Ti-6Al-4V ELI alloy consisted of the acicular martensitic $\alpha^{\prime}$ phase. Liu et al. [17] reported that the metastable $\alpha^{\prime}$-phase with a deformed lattice structure had the highest strength among all combinations of phase constituents possible in the Ti-6Al-4V alloy, but 
with reduced plasticity. Heat treatment is generally applied to the Ti-6Al-4V alloy after fabrication to develop the microstructure for enhanced ductility and fracture toughness. The heat treatments applied to the Ti-6Al-4V alloy below and above the $\beta$ transus $\left(1000^{\circ} \mathrm{C}\right)$ are referred to as sub-transus and super-transus heat treatments, respectively $[35,52]$. For a complete decomposition of $\alpha^{\prime}$, Beese et al. [20] reported the temperature required to be $780{ }^{\circ} \mathrm{C}$, while Vilaro et al. [53] reported $800{ }^{\circ} \mathrm{C}$. In this study, the stress relief heat treatment was carried out at $670^{\circ} \mathrm{C}$ for $5 \mathrm{~h}$, followed by furnace cooling, and therefore, complete decomposition was not observed. In fact, the $\beta$ phase was not observed by XRD after stress relief heat treatment, potentially due to instrumental limitation, although Baghi et al. [54] reported the presence of the $\beta$ phase after stress relief at $670{ }^{\circ} \mathrm{C}$. The presence of a fine acicular $\alpha^{\prime}$ microstructure would contribute to the higher strength and lower ductility observed for the ASR samples [20,55]. The presence of $\alpha^{\prime}$ will incur lattice strains, which is why it is stronger than the lamellar $\alpha+\beta$ phase [17]. Yang et al. [56] reported that the high density of dislocations was observed in $\alpha^{\prime}$ martensite, which also contributes to hardening via dislocation strengthening.

HIP was performed at $920^{\circ} \mathrm{C}$ for $2 \mathrm{~h}$ with a gas pressure of $100 \mathrm{MPa}$ under an $\mathrm{Ar}$ atmosphere followed by controlled air cooling. The temperature of HIP was above the $\alpha^{\prime}$ decomposition temperature, and therefore, the HIP samples exhibited a fine lamellar mixture of $\alpha+\beta$ phases due to decomposition of the $\alpha^{\prime}(\mathrm{hcp})$ phase. Due to this phase transformation, the strength of the HIP Ti-6Al-4V alloy samples decreased while ductility increased after the utilization of HIP. On average, the yield strength of the ASR samples decreased from $1141 \pm 22 \mathrm{MPa}$ to $928 \pm 12 \mathrm{MPa}$, tensile strength decreased from $1190 \pm 15$ to $1003 \pm 3 \mathrm{MPa}$, and ductility increased from $6.9 \pm 2.3 \%$ to $16.1 \pm 0.6 \%$ after HIP. Utilization of HIP would close the lack-of-fusion flaws and keyhole pores, making the alloy considerably more ductile and isotropic, however, with a slight decrease in strength due to the phase transformation.

The mechanical behavior of the HIP samples was observed to be more consistent and isotropic compared to the ASR samples. As reported in Table 3 and Figures 2 and 3, all of the mechanical properties quantified including yield strength, tensile strength, elongation at fracture, Young's modulus, modulus of toughness, and Vickers hardness were quite consistent, regardless of build directions after HIP at $920{ }^{\circ} \mathrm{C}$ for $2 \mathrm{~h}$ with $100 \mathrm{MPa}$ under an Ar atmosphere, followed by controlled air cooling. Therefore, there was no significant mechanical anisotropy to be reported for the Ti-6Al-4V ELI alloy produced by LPBF after the proper HIP. This finding is different from the work of Qiu et al. [22], who reported that the difference in ductility between the horizontally and vertically built samples persisted even after $\mathrm{HIP}$ at $920^{\circ} \mathrm{C}$ for $4 \mathrm{~h}$ at $103 \mathrm{MPa}$, followed by furnace cooling. Baghi et al. [57] recently documented the concurrent influence of machining (e.g., surface roughness) and build direction on the mechanical behavior of the Ti-6Al-4V alloy as a function of stress-relief and further thermal annealing.

Significant anisotropy in the form of low ductility and low modulus of toughness was observed in ASR samples built in the Z-direction (i.e., sample series C), as reported in Table 2 and Figures 2 and 3. Fracture surfaces from the ASR sample series C with very low ductility and toughness exhibited a significant presence of pockets, as shown in Figure 5, which are keyhole pores based on the size of these pockets, ranging from 30 to $100 \mu \mathrm{m}$. These pockets were not observed frequently in any of the fracture surfaces of the HIP samples.

\section{Summary}

The present study investigated the mechanical properties, fracture surface, and microstructure of Ti-6Al-4V ELI (Grade 23) tensile rods produced by LPBF after stress-relief and hot isostatic pressing using quasi-static tension test at room temperature. The main findings from the study are:

1. Regardless of build direction, the mechanical properties of LPBF Ti-6Al-4V ELI alloy examined by quasi-static tension were consistent and isotropic after hot isostatic 
pressing (following stress relief treatment at $670{ }^{\circ} \mathrm{C}$ for $5 \mathrm{~h}$ ) at $920{ }^{\circ} \mathrm{C}$ for $2 \mathrm{~h}$ with a pressure of $100 \mathrm{MPa}$ under an Ar atmosphere.

2. The ASR samples in general had a higher strength and lower ductility along with the presence of a fine acicular $\alpha^{\prime}$ phase, while the HIP samples had lower strength and higher ductility. The ASR samples built in the build Z-direction had the lowest ductility at 3.8\%. This significant anisotropy in ductility for ASR samples built in the $\mathrm{Z}$ direction was mainly due to the presence of keyhole porosity associated with the LPBF process.

3. The mechanical behavior of the HIP samples was more consistent, isotropic, and can be reported as a yield strength of $928 \pm 12 \mathrm{MPa}$, tensile strength of $1003 \pm 3 \mathrm{MPa}$, $16.1 \pm 0.6 \%$ elongation at fracture, modulus of toughness of $153 \pm 5 \mathrm{~J} / \mathrm{m}^{3}$, Young's modulus of $115 \pm 2 \mathrm{GPa}$, and hardness of $303 \pm 1 \mathrm{HV}$.

4. The microstructure of the as-stress-relieved samples was dominated by a fine acicular martensitic $\alpha^{\prime}$ phase due to rapid solidification associated with the LPBF. After HIP treatment at $920^{\circ} \mathrm{C}$ for $2 \mathrm{~h}$ with $100 \mathrm{MPa}$, the fine acicular martensitic $\alpha^{\prime}$ transformed into a fine lamellar mixture of $\alpha$ and $\beta$ phases. Utilization of HIP would close the lackof-fusion flaws and keyhole pores, making the alloy considerably more ductile and isotropic, however, with a slight decrease in strength due to the phase transformations.

Author Contributions: Conceptualization, D.D.I., N.E.W., D.M.W. and Y.S.; Formal analysis, A.M. (Asif Mahmud), T.H., L.Z., H.H. and A.M. (Abhishek Mehta); Investigation, A.M. (Asif Mahmud), T.H., L.Z., H.H. and A.M. (Abhishek Mehta); Methodology, A.M. (Asif Mahmud), T.H., H.H. and A.M. (Abhishek Mehta); Writing—original draft, A.M. (Asif Mahmud) and Y.S.; Writing—review and editing, A.M. (Asif Mahmud), D.D.I., N.E.W., D.M.W. and Y.S.; Supervision, Y.S.; Funding acquisition, D.D.I., N.E.W., D.M.W. and Y.S. All authors have read and agreed to the published version of the manuscript.

Funding: This research was sponsored by the Battelle Energy Alliances, LLC under contract no. DE-AC07-05ID14517-214376 with collaboration from the authors of the Idaho National Laboratory. The views, opinions, and conclusions made in this document are those of the authors and should not be interpreted as representing the official policies, either expressed or implied, of the Battelle Energy Alliances, Idaho National Laboratory, or the U.S. Government. The U.S. Government is authorized to reproduce and distribute reprints for government purposes notwithstanding any copyright notation herein.

Data Availability Statement: The data presented in this study are available on request from the corresponding author.

Conflicts of Interest: The authors declare no conflict of interest.

\section{References}

1. Gu, D.D.; Meiners, W.; Wissenbach, K.; Poprawe, R. Laser additive manufacturing of metallic components: Materials, processes and mechanisms. Int. Mater. Rev. 2013, 57, 133-164. [CrossRef]

2. Simonelli, M.; Tse, Y.Y.; Tuck, C. Effect of the build orientation on the mechanical properties and fracture modes of SLM Ti-6Al-4V. Mater. Sci. Eng. A 2014, 616, 1-11. [CrossRef]

3. Carroll, B.E.; Palmer, T.A.; Beese, A.M. Anisotropic tensile behavior of Ti-6Al-4V components fabricated with directed energy deposition additive manufacturing. Acta Mater. 2015, 87, 309-320. [CrossRef]

4. Lewandowski, J.J.; Seifi, M. Metal Additive Manufacturing: A Review of Mechanical Properties. Annu. Rev. Mater. Res. 2016, 46, 151-186. [CrossRef]

5. Kok, Y.; Tan, X.P.; Wang, P.; Nai, M.L.S.; Loh, N.H.; Liu, E.; Tor, S.B. Anisotropy and heterogeneity of microstructure and mechanical properties in metal additive manufacturing: A critical review. Mater. Des. 2018, 139, 565-586. [CrossRef]

6. Frazier, W.E. Metal Additive Manufacturing: A Review. J. Mater. Eng. Perform. 2014, 23, 1917-1928. [CrossRef]

7. Gorsse, S.; Hutchinson, C.; Goune, M.; Banerjee, R. Additive manufacturing of metals: A brief review of the characteristic microstructures and properties of steels, Ti-6Al-4V and high-entropy alloys. Sci. Technol. Adv. Mater. 2017, 18, 584-610. [CrossRef]

8. DebRoy, T.; Wei, H.L.; Zuback, J.S.; Mukherjee, T.; Elmer, J.W.; Milewski, J.O.; Beese, A.M.; Wilson-Heid, A.; De, A.; Zhang, W. Additive manufacturing of metallic components-Process, structure and properties. Prog. Mater. Sci. 2018, 92, 112-224. [CrossRef]

9. Sallica-Leva, E.; Jardini, A.L.; Fogagnolo, J.B. Microstructure and mechanical behavior of porous Ti-6Al-4V parts obtained by selective laser melting. J. Mech. Behav. Biomed. Mater. 2013, 26, 98-108. [CrossRef] 
10. Yadroitsev, I.; Krakhmalev, P.; Yadroitsava, I. Selective laser melting of Ti6Al4V alloy for biomedical applications: Temperature monitoring and microstructural evolution. J. Alloys Compd. 2014, 583, 404-409. [CrossRef]

11. Xu, W.; Sun, S.; Elambasseril, J.; Liu, Q.; Brandt, M.; Qian, M. Ti-6Al-4V Additively Manufactured by Selective Laser Melting with Superior Mechanical Properties. J. Met. Mater. Miner. 2015, 67, 668-673. [CrossRef]

12. Qian, M.; Xu, W.; Brandt, M.; Tang, H.P. Additive manufacturing and postprocessing of Ti-6Al-4V for superior mechanical properties. MRS Bull. 2016, 41, 775-784. [CrossRef]

13. Wu, S.Q.; Lu, Y.J.; Gan, Y.L.; Huang, T.T.; Zhao, C.Q.; Lin, J.J.; Guo, S.; Lin, J.X. Microstructural evolution and microhardness of a selective-laser-melted Ti-6Al-4V alloy after post heat treatments. J. Alloys Compd. 2016, 672, 643-652. [CrossRef]

14. Khorasani, A.; Gibson, I.; Goldberg, M.; Littlefair, G. On the role of different annealing heat treatments on mechanical properties and microstructure of selective laser melted and conventional wrought Ti-6Al-4V. Rapid Prototyp. J. 2017, 23, 295-304. [CrossRef]

15. Wang, D.; Dou, W.; Yang, Y. Research on Selective Laser Melting of Ti6Al4V: Surface Morphologies, Optimized Processing Zone, and Ductility Improvement Mechanism. Metals 2018, 8, 471. [CrossRef]

16. Khorasani, A.M.; Gibson, I.; Ghaderi, A.; Mohammed, M.I. Investigation on the effect of heat treatment and process parameters on the tensile behaviour of SLM Ti-6Al-4V parts. Int. J. Adv. Manuf. Technol. 2018, 101, 3183-3197. [CrossRef]

17. Liu, S.; Shin, Y.C. Additive manufacturing of Ti6Al4V alloy: A review. Mater. Des. 2019, 164, 107552. [CrossRef]

18. Xu, W.; Brandt, M.; Sun, S.; Elambasseril, J.; Liu, Q.; Latham, K.; Xia, K.; Qian, M. Additive manufacturing of strong and ductile Ti-6Al-4V by selective laser melting via in situ martensite decomposition. Acta Mater. 2015, 85, 74-84. [CrossRef]

19. Xu, W.; Lui, E.W.; Pateras, A.; Qian, M.; Brandt, M. In situ tailoring microstructure in additively manufactured Ti-6Al-4V for superior mechanical performance. Acta Mater. 2017, 125, 390-400. [CrossRef]

20. Beese, A.M.; Carroll, B.E. Review of Mechanical Properties of Ti-6Al-4V Made by Laser-Based Additive Manufacturing Using Powder Feedstock. J. Met. Mater. Miner. 2015, 68, 724-734. [CrossRef]

21. Liu, J.; Jin, Y.; Fang, X.; Chen, C.; Feng, Q.; Liu, X.; Chen, Y.; Suo, T.; Zhao, F.; Huang, T.; et al. Dislocation Strengthening without Ductility Trade-off in Metastable Austenitic Steels. Sci. Rep. 2016, 6, 35345. [CrossRef]

22. Qiu, C.; Adkins, N.J.E.; Attallah, M.M. Microstructure and tensile properties of selectively laser-melted and of HIPed laser-melted Ti-6Al-4V. Mater. Sci. Eng. A 2013, 578, 230-239. [CrossRef]

23. Thijs, L.; Verhaeghe, F.; Craeghs, T.; Humbeeck, J.V.; Kruth, J.-P. A study of the microstructural evolution during selective laser melting of Ti-6Al-4V. Acta Mater. 2010, 58, 3303-3312. [CrossRef]

24. Edwards, P.; Ramulu, M. Fatigue performance evaluation of selective laser melted Ti-6Al-4V. Mater. Sci. Eng. A 2014, 598, 327-337. [CrossRef]

25. Parry, L.; Ashcroft, I.A.; Wildman, R.D. Understanding the effect of laser scan strategy on residual stress in selective laser melting through thermo-mechanical simulation. Addit. Manuf. 2016, 12, 1-15. [CrossRef]

26. Mishurova, T.; Cabeza, S.; Artzt, K.; Haubrich, J.; Klaus, M.; Genzel, C.; Requena, G.; Bruno, G. An Assessment of Subsurface Residual Stress Analysis in SLM Ti-6Al-4V. Materials 2017, 10, 348. [CrossRef] [PubMed]

27. Gloaguen, D.; Girault, B.; Courant, B.; Dubos, P.-A.; Moya, M.-J.; Edy, F.; Rebelo Kornmeier, J. Study of Residual Stresses in Additively Manufactured Ti-6Al-4V by Neutron Diffraction Measurements. Metall. Mater. Trans. A 2019, 51, 951-961. [CrossRef]

28. Yadroitsev, I.; Yadroitsava, I.; Plessis, A.D.; MacDonald, E. Fundamentals of Laser Powder Bed Fusion of Metals, 1st ed.; Elsevier: Amsterdam, The Netherlands, 2021; pp. 245-276.

29. Syed, A.K.; Ahmad, B.; Guo, H.; Machry, T.; Eatock, D.; Meyer, J.; Fitzpatrick, M.E.; Zhang, X. An experimental study of residual stress and direction-dependence of fatigue crack growth behaviour in as-built and stress-relieved selective-laser-melted Ti6Al4V. Mater. Sci. Eng. A 2019, 755, 246-257. [CrossRef]

30. Hrabe, N.; Gnäupel-Herold, T.; Quinn, T. Fatigue properties of a titanium alloy (Ti-6Al-4V) fabricated via electron beam melting (EBM): Effects of internal defects and residual stress. Int. J. Fatigue 2017, 94, 202-210. [CrossRef]

31. Wauthle, R.; Vrancken, B.; Beynaerts, B.; Jorissen, K.; Schrooten, J.; Kruth, J.-P.; Van Humbeeck, J. Effects of build orientation and heat treatment on the microstructure and mechanical properties of selective laser melted Ti6Al4V lattice structures. Addit Manuf. 2015, 5, 77-84. [CrossRef]

32. Leuders, S.; Thöne, M.; Riemer, A.; Niendorf, T.; Tröster, T.; Richard, H.A.; Maier, H.J. On the mechanical behaviour of titanium alloy TiAl6V4 manufactured by selective laser melting: Fatigue resistance and crack growth performance. Int. J. Fatigue 2013, 48, 300-307. [CrossRef]

33. Tao, P.; Li, H.-X.; Huang, B.-Y.; Hu, Q.-D.; Gong, S.-L.; Xu, Q.-Y. Tensile behavior of Ti-6Al-4V alloy fabricated by selective laser melting: Effects of microstructures and as-built surface quality. China Foundry 2018, 15, 243-252. [CrossRef]

34. Kasperovich, G.; Hausmann, J. Improvement of fatigue resistance and ductility of TiAl6V4 processed by selective laser melting. J. Mater. Process. Technol. 2015, 220, 202-214. [CrossRef]

35. Vrancken, B.; Thijs, L.; Kruth, J.-P.; Van Humbeeck, J. Heat treatment of Ti6Al4V produced by Selective Laser Melting: Microstructure and mechanical properties. J. Alloys Compd. 2012, 541, 177-185. [CrossRef]

36. Cao, S.; Hu, Q.; Huang, A.; Chen, Z.; Sun, M.; Zhang, J.; Fu, C.; Jia, Q.; Lim, C.V.S.; Boyer, R.R.; et al. Static coarsening behaviour of lamellar microstructure in selective laser melted Ti-6Al-4V. J. Mater. Sci. Technol. 2019, 35, 1578-1586. [CrossRef]

37. Yan, X.; Yin, S.; Chen, C.; Huang, C.; Bolot, R.; Lupoi, R.; Kuang, M.; Ma, W.; Coddet, C.; Liao, H.; et al. Effect of heat treatment on the phase transformation and mechanical properties of Ti6Al4V fabricated by selective laser melting. J. Alloys Compd. 2018, 764, 1056-1071. [CrossRef] 
38. Ti-6Al-4V (Ti0.94V0.01Al0.05 rt) Crystal Structure: Datasheet from “PAULING FILE Multinaries Edition—2012" in SpringerMaterials. Available online: https://materials.springer.com/isp/crystallographic/docs/sd_1931746 (accessed on 17 October 2020).

39. Stephens, P.W. Rietveld Refinement. In Uniting Electron Crystallography and Powder Diffraction, 1st ed.; Kolb, U., Shankland, K., Meshi, L., Avilov, A., David, W., Eds.; Springer: Dordrecht, The Netherlands, 2011; pp. 15-26.

40. Rafi, H.K.; Karthik, N.V.; Gong, H.; Starr, T.L.; Stucker, B.E. Microstructures and Mechanical Properties of Ti6Al4V Parts Fabricated by Selective Laser Melting and Electron Beam Melting. J. Mater. Eng. Perform. 2013, 22, 3872-3883. [CrossRef]

41. Yu, J.; Rombouts, M.; Maes, G.; Motmans, F. Material Properties of Ti6Al4V Parts Produced by Laser Metal Deposition. Phys. Procedia 2012, 39, 416-424. [CrossRef]

42. Facchini, L.; Magalini, E.; Robotti, P.; Molinari, A.; Höges, S.; Wissenbach, K. Ductility of a Ti-6Al-4V alloy produced by selective laser melting of prealloyed powders. Rapid Prototyp J. 2010, 16, 450-459. [CrossRef]

43. Attallah, M.M.; Zabeen, S.; Cernik, R.J.; Preuss, M. Comparative determination of the $\alpha / \beta$ phase fraction in $\alpha+\beta$-titanium alloys using X-ray diffraction and electron microscopy. Mater. Charact. 2009, 60, 1248-1256. [CrossRef]

44. Pederson, R. Microstructure and Phase Transformation of Ti-6Al-4V. Ph.D. Thesis, Luleå University of Technology, Luleå, Sweden, 2002.

45. Motyka, M. Martensite formation and decompostion during Traditional and AM processing of Two-Phase Titanium Alloys-An Overview. Metals 2021, 11, 481. [CrossRef]

46. Sofinowski, K.; Šmíd, M.; Kuběna, I.; Vivès, S.; Casati, N.; Godet, S.; Van Swygenhoven, H. In situ characterization of a high work hardening Ti-6Al-4V prepared by electron beam melting. Acta Mater. 2019, 179, 224-236. [CrossRef]

47. Fultz, J.H.B. Transmission Electron Microscopy and Diffractometry of Materials, A.6 Indexed Single Crystal Diffraction Patterns, 3rd ed.; Springer: Berlin/Heidelberg, Germany; New York, NY, USA, 2004; pp. 709-711.

48. Lifshitz, M.; Slyozov, V.V. The kinetics of precipitation from supersaturated solid solutions. J. Phys. Chem. Solids 1961, 19, 35-50. [CrossRef]

49. Semiatin, S.L.; Kirby, B.C.; Salishchev, G.A. Coarsening Behavior of an Alpha-Beta Titanium Alloy. Metall. Mater. Trans. A 2004, 35A, 2809-2819. [CrossRef]

50. Xu, J.; Zeng, W.; Jia, Z.; Sun, X.; Zhao, Y. Coarsening Kinetics and Morphological Evolution in a Two-Phase Titanium Alloy During Heat Treatment. J. Mater. Eng. Perform. 2016, 25, 734-743. [CrossRef]

51. Xu, J.; Zeng, W.; Sun, X.; Jia, Z.; Zhou, J. Static coarsening behavior of the lamellar alpha in Ti-17 alloy. J. Alloys Compd. 2015, 631, 248-254. [CrossRef]

52. Zuback, J.S.; DebRoy, T. The Hardness of Additively Manufactured Alloys. Materials 2018, 11, 2070. [CrossRef]

53. Vilaro, T.; Colin, C.; Bartout, J.D. As-Fabricated and Heat-Treated Microstructures of the Ti-6Al-4V Alloy Processed by Selective Laser Melting. Metall. Mater. Trans. A 2011, 42, 3190-3199. [CrossRef]

54. Baghi, A.D.; Nafisi, S.; Hashemi, R.; Edendorff-Heiderpriem, H.; Ghomashchi, R. Effective Post Processing of SLM Fabricated Ti-6Al-4V Alloy: Machining vs Thermal Treatment. J. Manuf. Proc. 2021, 68, 1031-1046. [CrossRef]

55. Gong, H.; Rafi, K.; Gu, H.; Janaki Ram, G.D.; Starr, T.; Stucker, B. Influence of defects on mechanical properties of Ti-6Al-4V components produced by selective laser melting and electron beam melting. Mater. Des. 2015, 86, 545-554. [CrossRef]

56. Yang, J.; Yu, H.; Yin, J.; Gao, M.; Wang, Z.; Zeng, X. Formation and control of martensite in Ti-6Al-4V alloy produced by selective laser melting. Mater. Des. 2016, 108, 308-318. [CrossRef]

57. Baghi, A.D.; Nafisi, S.; Hashemi, R.; Edendorff-Heiderpriem, H.; Ghomashchi, R. Experimental Realisation of Build Orientation Effects on The Mechanical Properties of Truly As-Built Ti-6Al-4V SLM Parts. J. Manuf. Proc. 2021, 64, 140-152. [CrossRef] 